\title{
Effect of cross section on collapse load in pipe bends subjected to in-plane closing moment
}

\author{
T. Christo Michael ${ }^{1}$, AR. Veerappan ${ }^{1} *$, S.S. Shanmugam ${ }^{1}$ \\ ${ }^{1}$ Department of Mechanical Engineering, National Institute of Technology Tiruchirappalli, INDIA \\ ${ }^{*}$ Corresponding Author: e-mail: aveer@nitt.edu, Tel +91-0431-2503416, Fax.+91-0431-2500133
}

\begin{abstract}
A comparison between pipe bends with assumed cross sections, namely elliptic and semi oval to include ovality along with wall thinning, was performed to determine the plastic collapse load under in-plane closing bending moment using finite element limit analysis based on an elastic-perfectly plastic material considering geometric nonlinearity. Twice-elastic-slope method was used to obtain collapse load from the moment-rotation curve drawn for each pipe bend model considered. The effect of ovality on collapse load is significant and higher for elliptic cross sections for almost all cases while the thinning effect is negligible for both the cross sections. The study concludes that the use of elliptic cross section is suitable for analyzing pipe bend with ovality. Therefore, a closed-form solution is proposed to determine collapse load of pipe bend based on the finite element results of elliptic cross sections.
\end{abstract}

Keywords: Collapse load. Ovality. Pipe bend. Thinning. Twice-elastic-slope.

DOI: http://dx.doi.org/10.4314/ijest.v3i6.20

\section{Introduction}

Pipe bends are critical components in piping systems and generally are recognized to be the most economical means of changing directions while providing flexibility and end reactions to piping systems within the allowable limits. Determination of limit load in pipe bends, under bending with and without internal fluid pressure loads, by analytical (Spence and Findlay, 1973; Calladine, 1974; Goodall, 1978), experimental (Yahiaoui et al, 2000; 2002; Hilsenkopf et al, 1998) and numerical (Suneel et al, 2007; Shalaby and Younan, 1998; Chattopadhyay et al, 2000; Robertson et al, 2005; Kim and Oh, 2006; Kim et al, 2008) methods can be found in literature. Also various researchers have estimated the plastic loads of pipe bends with cracks (Hong et al, 2010; Kim et al, 2011).

All existing works with regard to the determination of plastic loads, except the work of Kim et al. (2008), assume the cross section of the pipe bend to be circular with uniform thickness. Kim et al. (2008) provided a method to estimate plastic loads for elbows with non-uniform thicknesses.

In reality, the pipe bend exists with shape imperfections namely ovality and thinning/thickening as the result of the bending process. The acceptability of pipe bend depends on the magnitude of ovality and thinning (Veerappan and Shanmugam, 2008). Therefore, it is more relevant to include ovality and thinning in the analysis of pipe bend. When ovality is included, the cross sections assumed, in the analysis of pipe bend, are elliptic (Dan, 2009) and semi oval (Boyle and Spence, 1981).

The objective of the study is to choose the suitable cross section to be used for the finite element (FE) analysis of pipe bend to include ovality. The present study compares the collapse loads of pipe bends modeled with elliptic and semi oval cross sections which include thinning when subjected to in-plane closing bending moment using finite element method.

\section{Definition}

2.1 Ovality (Elliptic): The degree of ovality is determined by the difference between the major and minor diameters divided by the nominal diameter of the pipe. When expressed in percentage form (Dan, 2009; Kale and Thorat, 2009; Veerappan et al, 2010) as in 
Equation (1a), it corresponds to percentage ovality.

$$
C_{0}=\frac{D_{\max }-D_{\min }}{D} \times 100
$$

where $D=\frac{D_{\max }+D_{\min }}{2}$

2.2 Ovality (Semi oval): The degree of ovality for semi oval cross section is determined by the difference between the nominal outside and minor radii divided by the nominal outside radius of the pipe. It is expressed in percentage form as in Equation (1b).

$$
C_{0}=\frac{r_{o}-r_{\min }}{r_{o}} \times 100
$$

2.3 Thinning: Thinning, which occurs at extrados of the pipe bend, is defined as the ratio of the difference between the nominal thickness and the minimum thickness to the nominal thickness of the pipe bend and is expressed in percentage (Veerappan and Shanmugam, 2008; Veerappan et al, 2010) as given in Equation (2).

$$
C_{\mathrm{t}}=\frac{t-t_{\min }}{t} \times 100
$$

2.4 Thickening: Thickening occurs at intrados and is defined as the difference between the maximum thickness and the nominal thickness divided by the nominal thickness of the pipe bend. The percentage thickening is given in Equation (3).

$$
C_{\mathrm{th}}=\frac{t_{\max }-t}{t} \times 100
$$

\section{Finite element limit analysis}

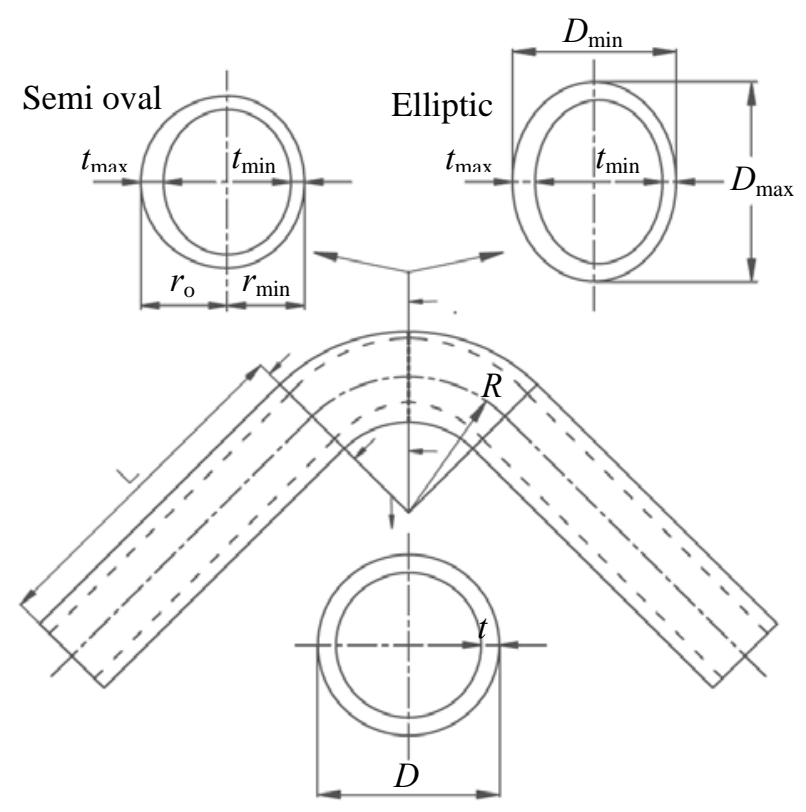

Circular cross section

Figure 1. Pipe bend with attached straight pipe showing elliptic and semi oval cross sections 
Table 1. Geometry of the pipe bends

\begin{tabular}{|c|c|c|c|}
\hline Sl.No. & $r / t$ & $R / r$ & $h$ \\
\hline 1 & \multirow{2}{*}{5} & 2 & 0.40 \\
\hline 2 & & 3 & 0.60 \\
\hline 3 & \multirow{2}{*}{10} & 2 & 0.20 \\
\hline 4 & & 3 & 0.30 \\
\hline 5 & \multirow{2}{*}{20} & 2 & 0.10 \\
\hline 6 & & 3 & 0.15 \\
\hline
\end{tabular}

The FE modeling and the limit analysis were carried out using ABAQUS (2009), a general nonlinear finite element package. A scripting language Python was used to develop the program which in turn created the pipe bend geometry, input material property, meshed the model, applied boundary and loading conditions and created input files. The input file was created adopting the method used in example 1.1.2 of ABAQUS example problems manual (ABAQUS, 2009).

3.1 Geometry: The piping system considered for the analysis comprises a $90^{\circ}$ bend and two attached equal length, $L$, straight pipes, $L=5 D$ (Dan, 2009), where $D$ is the nominal outside diameter of the pipe. The straight pipe attachment removes the end effects caused by the loading boundary conditions to the pipe bend. The 'reference' model, in this paper, corresponds to the pipe bend with circular cross section and uniform thickness. For the reference model, the mean radius and thickness of the pipe are denoted by $r$ and $t$ respectively, and the bend radius by $R$. The bend characteristic, $h$, is defined by

$$
h=\frac{R t}{r^{2}}=\frac{R / r}{r / t}
$$

The pipe bend geometric parameters chosen (Kim et al, 2008) for the present analyses are shown in Table 1. The 'irregular' model in this paper corresponds to the pipe bend with ovality and thinning. The geometry of the pipe bend includes ovality and thinning each varied from $0 \%$ to $20 \%$ in steps of $5 \%$ (Veerappan and Shanmugam, 2006) while the cross section of the straight pipe is circular with uniform (nominal) thickness for all the models. The models considered have the required ovality and thinning/thickening at the bend section (center of the pipe bend), and changes linearly moving away from the bend section. At the two ends where the pipe bend is connected to the straight pipes, as shown in Figure 1, the cross sections become circular with uniform thickness. The cross sections considered are elliptic and semi oval and it is assumed that the increase in thickness at intrados (thickening) is equal to the decrease in thickness at extrados (thinning). A total of 150 models for each cross section have been studied.

3.2 Finite element analysis: The material model was assumed to be elastic-perfectly plastic, and non-hardening $J_{2}$ flow theory was used. The material used was stainless steel (type 304) with Young's modulus $(E)$, yield stress $\left(\sigma_{0}\right)$ and Poisson's ratio $(v)$ respectively as 193 GPa, $272 \mathrm{MPa}$ and 0.26 (Shalaby and Younan, 1998). The C3D20R, 20-node quadratic brick, reduced integration element, having three degrees of freedom (translation in $\mathrm{x}, \mathrm{y}$ and $\mathrm{z}$ directions), was preferred in order to reduce computing time. Mapped meshing was used to generate the mesh model. The number of elements and nodes for each model were chosen as 3000 and 15777 respectively, after performing mesh refinements. Three such elements were used across the thickness for all the models. One half of the model which is symmetric with respect to the assumed bending plane, as shown in Figure 2 (a), was built and symmetry boundary condition was applied. All possible degrees of freedom (D.O.F.) at one end of the straight pipe was constrained, as shown in Figure 2 (b), and multipoint constraint was applied to the other end in which the end surface nodes were attached to a single node where rotation boundary condition was specified. Increments of rotation were prescribed at the free end rather than increments of moment since it is anticipated that the collapse will be unstable (Shalaby and Younan, 1998). The RIKS option within the package was invoked to avoid problems associated with convergence in elastic-perfectly plastic calculations.

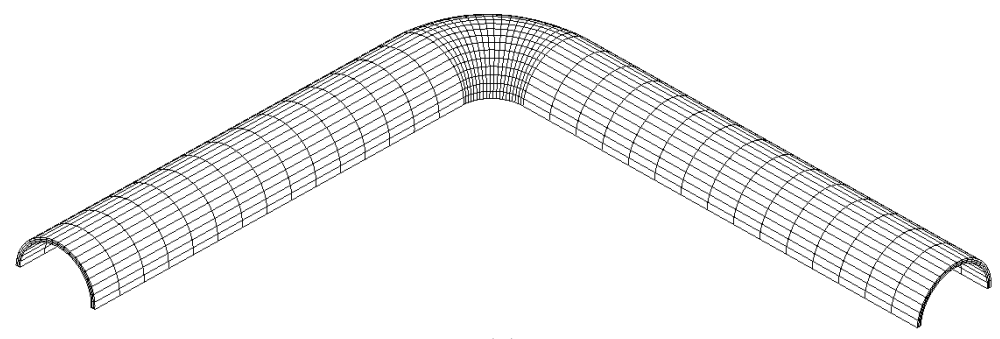

(a) 


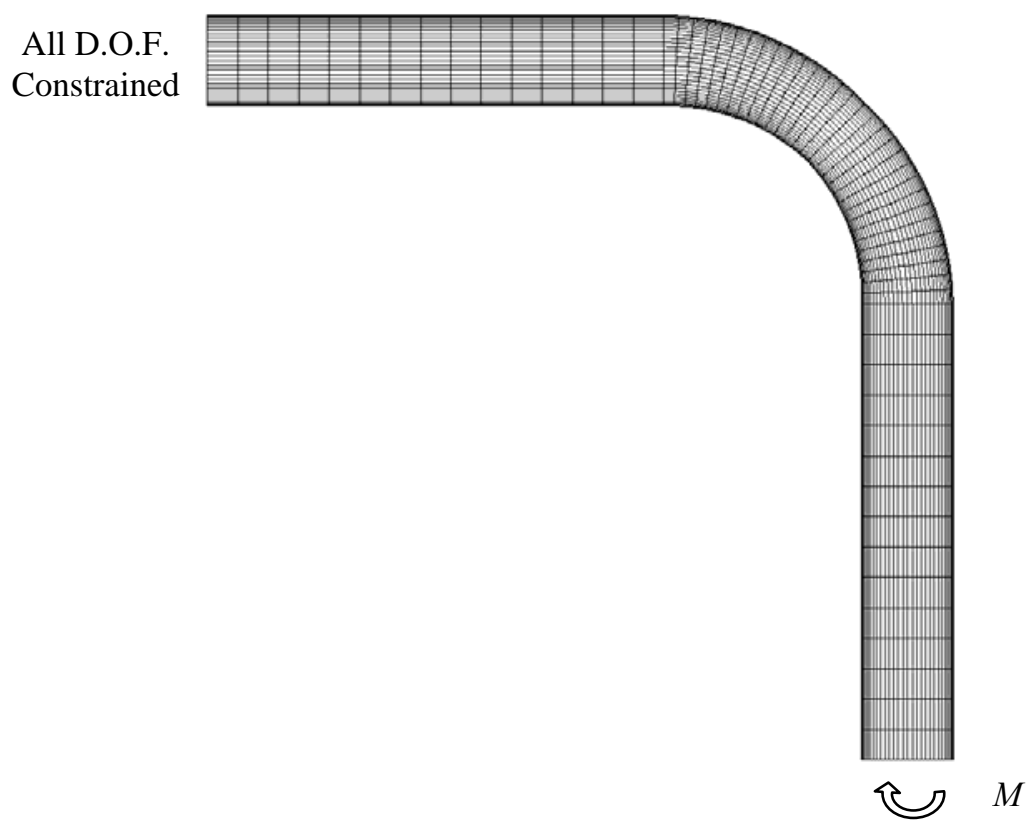

(b)

Figure 2. Finite element models showing (a) half symmetry and (b) boundary and loading conditions

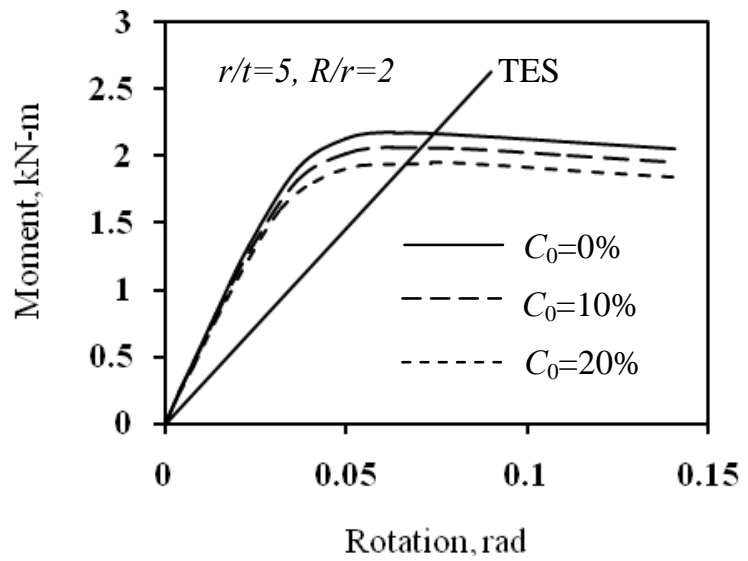

Figure 3. Typical moment-rotation curves of elliptic cross section

When a pipe bend is subject to in-plane closing moment, geometric weakening is present (Robertson et al, 2005), hence the GNL (Geometric Non-Linearity) was included in the analyses. The input files were created and submitted for solving the models. The reaction moments corresponding to the specified rotations at the MPC (Multi Point Constraint) node were extracted directly in Excel sheets. Using the moment and rotation data the curves were plotted. When nonlinear geometry effect is considered, the moment-rotation curves do not approach horizontal asymptote to obtain clear limiting loads as shown in Figure 3. Therefore, the twice-elastic-slope (TES) (Kim et al, 2010) method (in which a straight line from the origin with twice the slope of the initial elastic response of the moment-rotation curve is drawn to intersect the same curve) was used to determine the plastic collapse loads from FE moment-rotation curves. The maximum or instability loads (Shalaby and Younan, 1998) were reported as collapse load for the models as the instability point occurs before the TES point. 


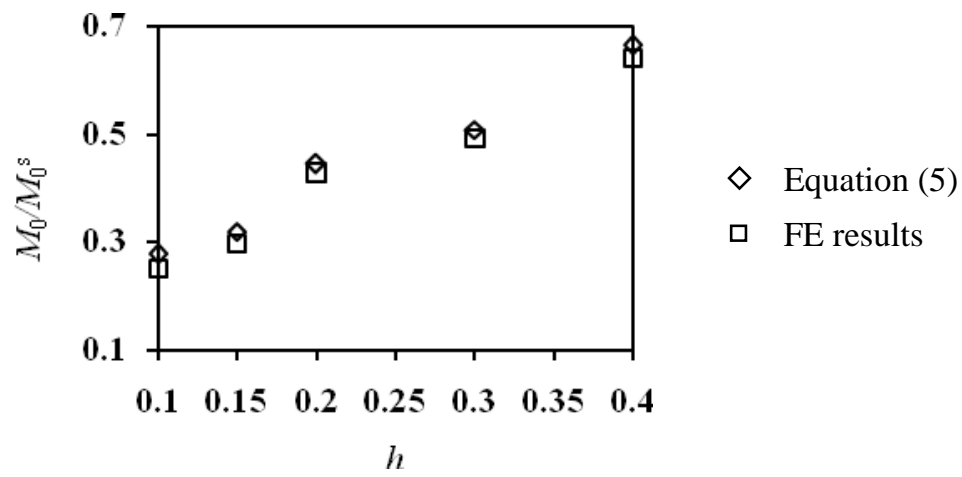

Figure 4. Comparison between Equation (5) and FE results of reference models

\section{Validity of FE models}

The present finite element limit analysis follows the limit analysis of Kim and Oh (2006). Hong et al. (2010) validated their results, based on the above mentioned finite element limit analysis, with the experimental results of Yahiaoui et al. (2000). Therefore, the finite element collapse load results of the present reference models were compared with the published collapse load solution of Kim and Oh (2006) as in Equation (5) under in-plane closing bending moment. Equation (5) was developed for bend characteristic, $h$, ranging from 0.1 to 0.5 , and is normalized with the limit moment of the straight pipe (Kim and Oh, 2006) as in Equation (6). Though $h$ considered for the present analyses ranges from 0.1 to 0.6 , the verification was carried out for $h$ up to 0.5 .

$$
\frac{M_{0}}{M_{0}^{s}}=0.800\left(\frac{r}{t}\right)^{-0.017}\left[h+1.460\left(\frac{r}{t}\right)^{-0.911}\right]^{n}
$$

where, $n=0.423\left(\frac{r}{t}\right)^{0.127}$

$$
M_{0}^{s}=4 \sigma_{0} r^{2} t
$$

$M_{0}$, in Equation (5) is the collapse moment of the pipe bends under in-plane bending moment, $M_{0}^{\mathrm{s}}$ is the limit moment of the straight pipe and $\sigma_{0}$ is the yield stress of the material. The comparison between FE results and the Equation (5) showed good agreement, as shown in Figure 4, with the average difference of 5.8\% and hence, the present FE modeling and analysis was validated.

\section{Results and discussion}

The percent difference between reference and irregular models of both elliptic and semi oval cross sections are shown in Figures 5 and 6 . The percent difference was calculated using the following formula.

$Z=\frac{M_{0}^{R e f}-M_{0}^{I g r}}{M_{0}^{R e f}}$, where $\mathrm{Z}$ is the percent difference, $M_{0}^{R e f}$ is the collapse moment of the reference models and $M_{0}^{I g r}$ is the collapse moment of irregular models for elliptic and semi oval cross sections.

The origin of the figures corresponds to the reference model. The effect of thinning, ovality and $r / t$ and $R / r$ on collapse load of the pipe bends are discussed below.

5.1 Effect of thinning: The combined effect of ovality and thinning, for $r / t=5$ and $R / r=2$, can be observed from Figure 5 . It is clear from the figure that the effect of thinning on the collapse load of the pipe bend models with elliptic and semi oval cross sections is minimal. The percent difference of the models with a particular ovality and any thinning is within $1.5 \%$. Similar trend has been observed for other geometries considered for both the cross sections. 

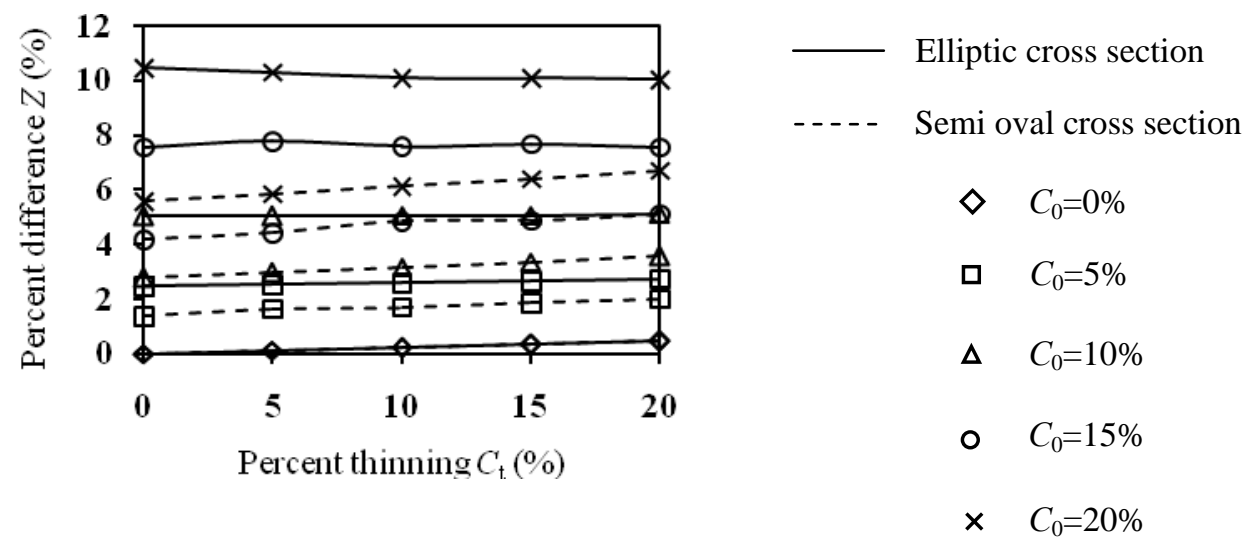

Figure 5. Effect of thinning for elliptic and semi oval cross sections for $r / t=5$ and $R / r=2$

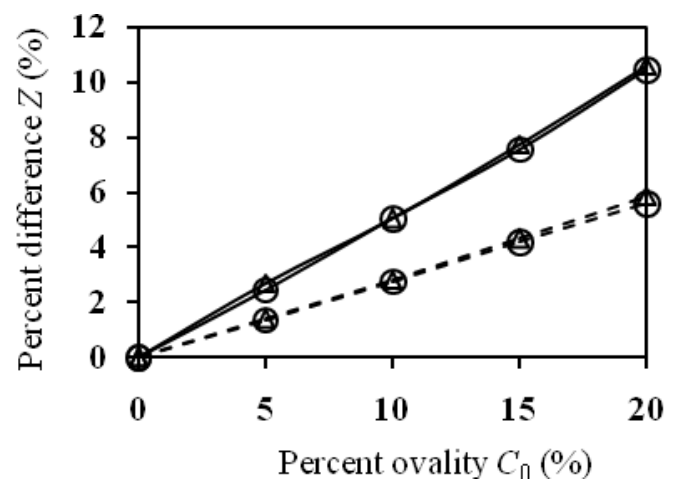

Figure 6 (a). Effect of ovality on collapse load for $r / t=5$

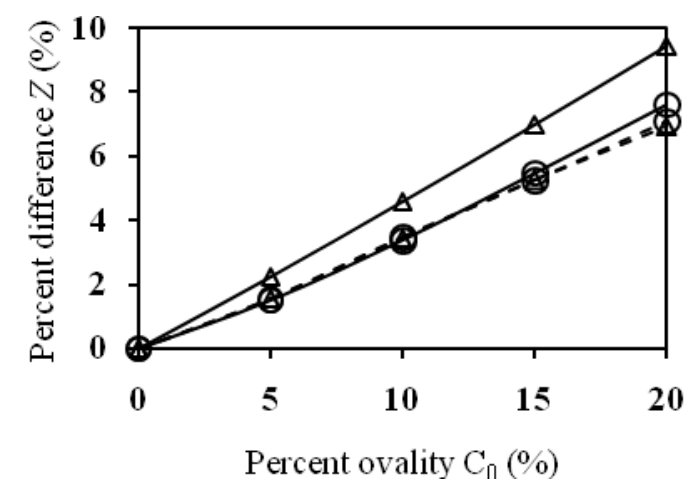

Figure 6 (c). Effect of ovality on collapse load for $r / t=20$

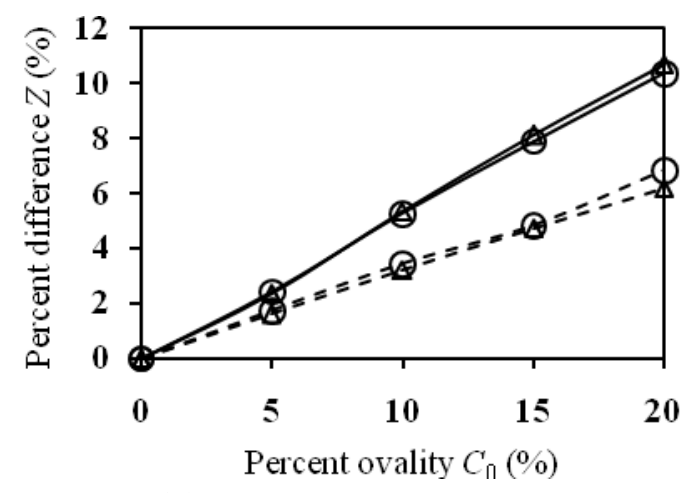

Figure 6 (b). Effect of ovality on collapse load for $r / t=10$

Figure 6. Effect of ovality on plastic load for various $R / r$ and $r / t$

3.2 Effect of ovality: Figure 6 depicts the effect of ovality on collapse load of pipe bend models with elliptic and semi oval cross sections. In all the cases, the percent difference between reference models and models with elliptic and semi oval cross sections increase with the increase in ovality. The influence of ovality is higher for the elliptic cross section than the semi oval cross section for all the models considered, except for the pipe bend geometry with $r / t=20$ and $R / r=2$ and 3 up to $10 \%$ ovality.

When $r / t=5$, for all ovality, the percent difference in the collapse load increases marginally as $R / r$ is increased from 2 to 3 for both elliptic and semi oval cross sections as shown in Figure 6 (a). Similar behaviour is observed for elliptic cross section as shown in Figure 6 (b), when $r / t=10$, except for the ovality of $5 \%$ in which the percent difference decreases with increasing $R / r$. The trend of $r / t=5$ is repeated for $r / t=20$ as well with considerable increase in percent difference for elliptic cross section, as shown in Figure 6 (c) The behaviour of semi oval cross section with $r / t=10$ and 20 is vice-versa of $r / t=5$ [Figures 6 (b) and (c)]. 


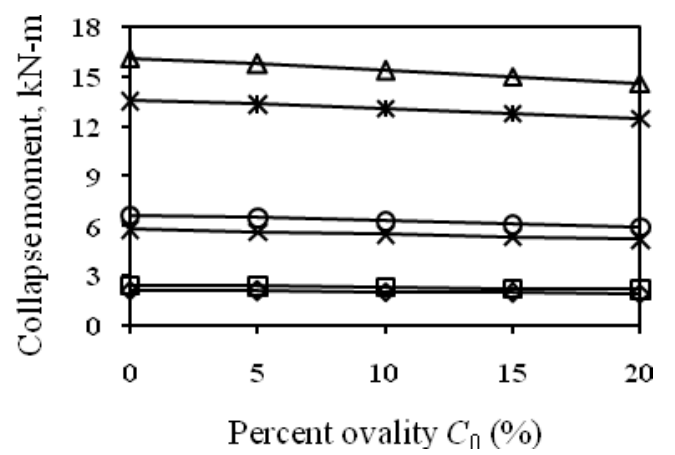

(a)

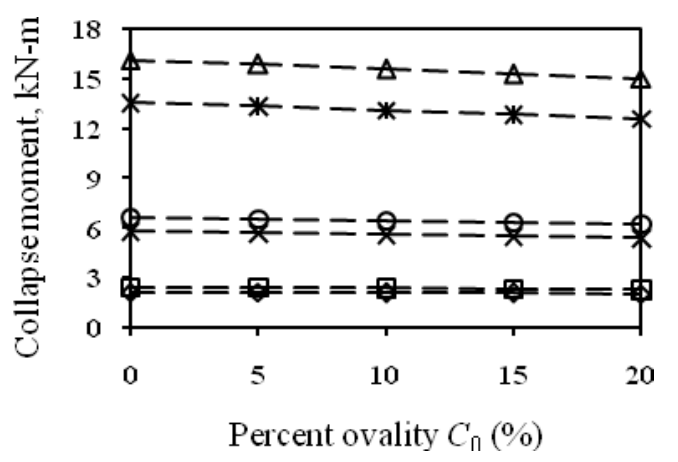

(b) $\begin{array}{ll}- & \text { Elliptic cross section } \\ \text { - - - - - Semi oval cross section }\end{array}$

$\Delta \quad r / t=20$ and $R / r=3$

* $r / t=20$ and $R / r=2$

○ $r / t=10$ and $R / r=3$

$\times r / t=10$ and $R / r=2$

ㅁ $r / t=5$ and $R / r=3$

$\diamond r / t=5$ and $R / r=2$

Figure 7. Magnitude of collapse moment of pipe bends with (a) elliptic cross section and (b) semi oval cross section

The effect of ovality can be interpreted by varying $r / t$ for a particular $R / r$. when $R / r=2$, for elliptic cross section, as $r / t$ is increased the percent difference decreases for $5 \%$ and $20 \%$ ovality whereas it increases and then decreases for the $10 \%$ and $15 \%$ ovality. For semi oval cross section, when $R / r=2$ and 3, the percent difference increases with increasing $r / t$ for all the ovality, except for the ovality of $5 \%$ in which the percent difference increase first and then decreases. When $R / r=3$, for elliptic cross section, the percent difference decreases as $r / t$ is increased for $5 \%$ ovality and the difference increase first and then decreases for other ovalities.

The percent difference of collapse load for the models considered ranges from $1.52 \%$ to $2.72 \%$ for elliptic cross section and from $1.38 \%$ to $1.72 \%$ for semi oval cross section when the ovality is $5 \%$. The range varies from $3.38 \%$ to $5.35 \%$ for elliptic cross section and from $2.78 \%$ to $3.47 \%$ for semi oval cross section as the ovality is increased to $10 \%$. The variation is from $5.48 \%$ to $8.1 \%$ for elliptic cross section and from $4.2 \%$ to $5.25 \%$ for semi oval cross section for the models with $15 \%$ ovality and the range is from $7.6 \%$ to $10.7 \%$ for elliptical cross section and from $5.6 \%$ to $7.1 \%$ for semi oval cross section when the ovality is further increased to $20 \%$.

5.1 Effect of $r / t$ and $R / r$ : For elliptic cross section the magnitude of the collapse load increases with increase in $r / t$ and $R / r$ as shown in Figure 7 (a). Similar behaviour is observed in Figure 7 (b) for semi oval cross section.

\section{Closed-form equation}

A closed-form solution is proposed, using regression analysis in Datafit package (Datafit, 2009), to include the effect of ovality in the calculation of collapse load of the pipe bends based on the FE results of the models with elliptic cross section as the effect of ovality on the collapse loads of the semi oval cross sections are less than the elliptic cross section. The normalized collapse moment in Equation (7) is a function of geometric parameters namely $r / t, R / r$ and $C_{0}$.

$$
\frac{M_{0}}{M_{0}^{s}}=1.5\left(\frac{r}{t}\right)^{-0.61}\left[\frac{R}{r}-\frac{1}{10}\left\{\frac{r\left(1+C_{0}\right)}{t}\right\}^{0.425}\right]^{0.2385}
$$



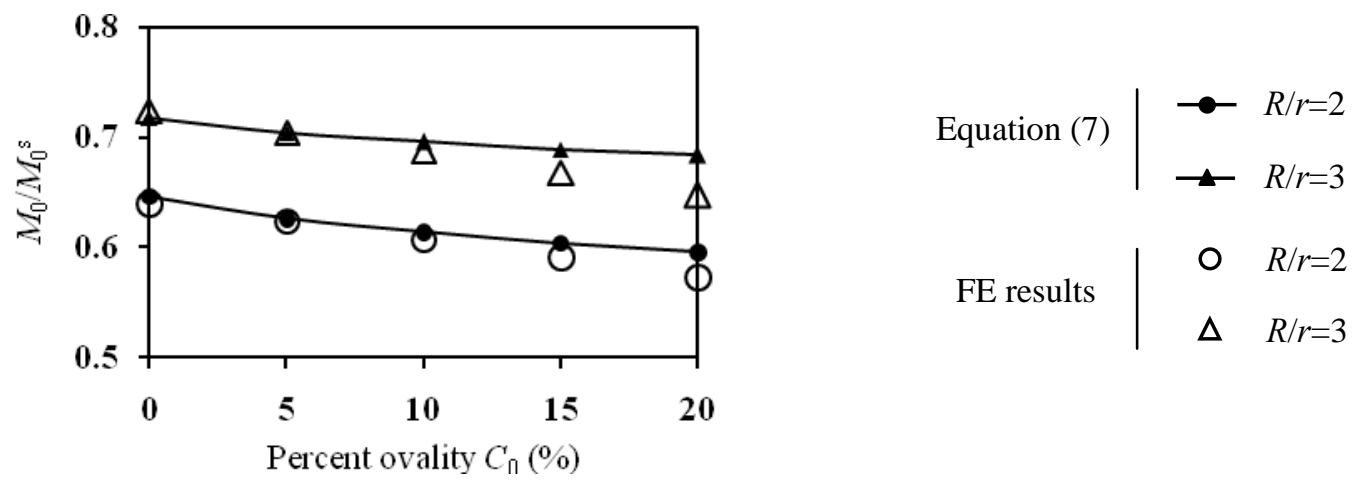

Figure 8 (a). Comparison for $r / t=5$

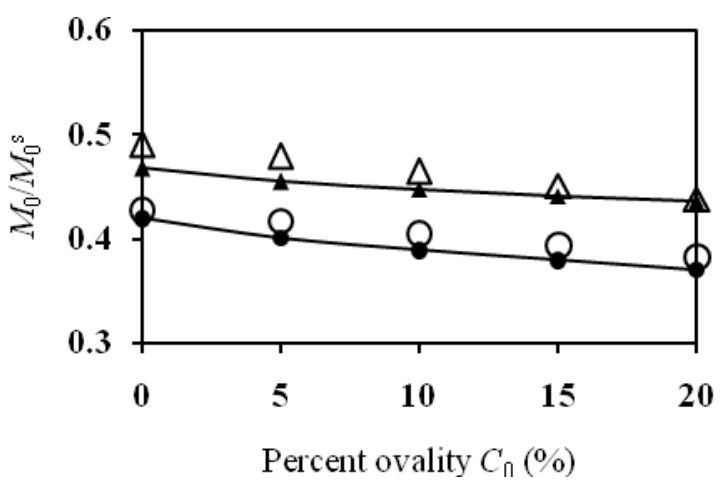

Figure 8 (b). Comparison for $r / t=10$

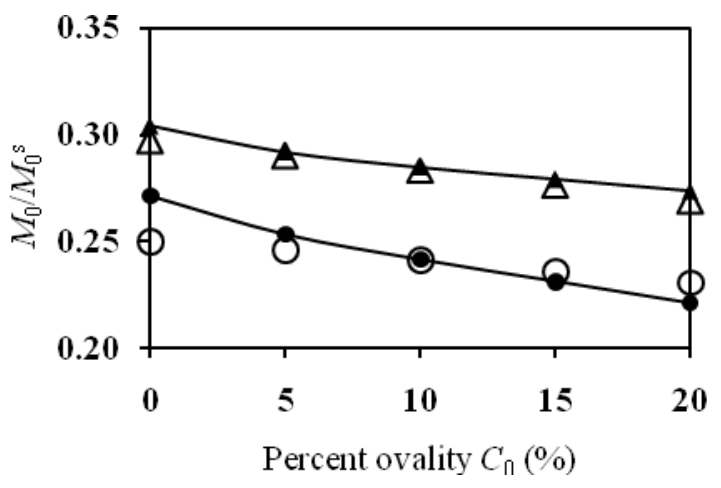

Figure 8 (c). Comparison for $r / t=20$

Figure 8. Comparison of FE results with the proposed equation

Equation (7) was compared with the finite element results, as shown in Figure 8, and the comparison shows good agreement with the average error of $2.6 \%$.

\section{Conclusions}

The comparison of assumed cross sections of pipe bend namely elliptic and semi oval that has been used to include ovality was performed using finite element limit analyses based on elastic-perfectly plastic material with large geometric change option. The thinning effect is also included along with ovality and each varied from $0 \%$ to $20 \%$ with the increment of $5 \%$. The following conclusions were drawn from the analyses.

o The effect of ovality is significant, as the ovality is increased from $0 \%$ to $20 \%$, while the thinning effect is not significant for both elliptic and semi oval cross sections of the pipe bend and therefore, analyses on pipe bend may exclude thinning. Also the thinning limit prescribed by various codes may be reconsidered

o The influence of ovality is higher for elliptic cross section for almost all the cases considered and hence elliptic cross section can be utilized to analyze pipe bend using finite element method when ovality is included

o Based on the finite element results of elliptic cross section, a mathematical equation is proposed to determine the collapse load of pipe bend with ovality

0 It is also found that the collapse load increases with increasing $r / t$ and $R / r$ for both the cross sections

The extension of the present work includes:

o The comparison of assumed cross sections, to include ovality, in the analysis pipe bends under in-plane bending with internal fluid pressure which is in progress.

o The study of comparison of assumed cross sections with actual cross section may be useful to quantify the approximation in the determination of collapse load. 


\section{Nomenclature}

FE $\quad$ Finite Element

TES Twice Elastic Slope

$C_{0} \quad$ Percent ovality

$C_{\mathrm{t}} \quad$ Percent thinning

$C_{\text {th }} \quad$ Percent thickening

$D \quad$ Nominal outside diameter of pipe (mm)

$D_{\max } \quad$ Maximum outside diameter of pipe (mm)

$D_{\min } \quad$ Minimum outside diameter of pipe (mm)

$h \quad$ Bend characteristic

$M_{0} \quad$ Collapse in-plane moment of pipe bend (kN-m).

$M_{0}{ }^{\mathrm{s}} \quad$ Limit in-plane moment of a straight pipe $(\mathrm{kN}-\mathrm{m})$.

$R \quad$ Bend radius (mm)

$r \quad$ Mean radius of pipe (mm)

$r_{\min } \quad$ Minimum radius in semi oval cross section (mm)

$r_{\mathrm{o}} \quad$ Nominal outside radius of pipe (mm)

$t \quad$ Nominal thickness of pipe (mm)

$t_{\max } \quad$ Maximum pipe thickness (mm)

$t_{\min } \quad$ Minimum pipe thickness (mm)

$\sigma_{0} \quad$ Yield stress of an elastic-perfectly plastic material

\section{References}

ABAQUS., 2009. User's manual. Version 6.9. Simulia Corporation, RI, USA.

Boyle J. T. and Spence J. A. 1981. Simple stress analysis for out-of -round pressurized pipe bends. International Journal of Pressure Vessels and Piping, Vol.9, pp. 251-261.

Calladine C. R. 1974. Limit analysis of curved tubes. Journal of Mechanical Engineering and Science, Vol.16, pp. 85-87.

Chattopadhyay J., Natahani D. K., Dutta B. K. and Kushwaha H. S. 2000. Closed-form collapse moment equations of elbows under internal pressure and in-plane bending moment. ASME Journal of Pressure Vessel Technology, Vol.122, pp. 431-436.

Dan V. 2009. The influence of the initial ovality tolerance on the nonlinear cycling analysis of pipe bends. ASME Journal of Pressure Vessel Technology, Vol.131, No. 041203, pp. 1-7.

Datafit, 2009. Oakdale Engineering, Version 9.0 Oakdale, PA, USA.

Goodall I. W. 1978. Lower bound limit analysis of curved tubes loaded by internal pressure and in-plane bending moment. $C E G B$ Report, $R D / B / N 4360$, Central Electricity Generating Board.

Hilsenkopf P., Boneh V. and Sollogoub P. 1998. Experimental study of behaviour and functional capability of ferric steel elbows and austenitic stainless steel thin-walled elbows. International Journal of Pressure Vessels and Piping, Vol.33, pp. 111-128.

Hong S.P., Kim J.H., Kim Y.J. and Budden P.J. 2010. Effect of internal pressure on plastic loads of 90_elbows with circumferential part-through surface cracks under in-plane bending. Engineering Fracture Mechanics, Vol.77, pp. 577-596.

Kale A. V. and Thorat H. T. 2009. Effect of precompression on ovality of pipe after bending. ASME Journal of Pressure Vessel Technology, Vol.131, No. 011207, pp. 1-7.

Kim N.H., Oh C.S., Kim Y.J., Kim J.S., Jerng D.W. and Budden P. J. 2011. Limit loads and fracture mechanics parameters for thickwalled pipes. International Journal of Pressure Vessels and Piping, Vol.88, pp. 403-414.

Kim Y. J., Je J. H., Oh C. S., Han J. J. and Budden P. J. 2010. Plastic loads for $90^{\circ}$ thick-walled elbows under combined pressure and bending. Journal of Strain Analysis, Vol.45, pp. 115-127.

Kim Y. J., Kim N. H., Oh C. Y. and Oh C. S. 2008. A method to estimate plastic loads for elbows with non-uniform thicknesses. Fatigue and Fracture of Engineering Materials and Structures, Vol.31, pp. 822-837.

Kim Y. J. and Oh C. S. 2006. Closed-form plastic collapse loads of pipe bends under combined pressure and in-plane bending. Engineering Fracture Mechanics, Vol.73, pp. 1437-1454.

Robertson A., Li H. and Mackenzie D. 2005. Plastic collapse of pipe bends under combined internal pressure and in-plane bending. International Journal of Pressure Vessels and Piping, Vol.82, pp. 407-416.

Shalaby M. A. and Younan M. Y. A. 1998. Limit loads for pipe elbows with internal pressure under in-plane closing moments. ASME Journal of Pressure Vessel Technology, Vol.120, pp. 35-42.

Spence J. and Findlay G. E., 1973. Limit load for elbows under in-plane bending, Proc. of the 2nd International Conference on Pressure Vessel Technology, San Antonio, USA, pp. 393-399.

Suneel K. G., Vivek B., Vaze K. K., Gosh A. K. and Kushwaha H. S. 2007. General limit load and B2 stress index equation for pipe bends under in-plane bending. Transactions, SMiRT, 19, Toronto, No. B04/5, pp. 1-8.

Veerappan AR. and Shanmugam S. 2006. Stress analysis of pipe bends subjected to internal fluid pressure using the finite element 
technique. Journal of Strain Analysis, Vol.41, No. 8, pp. 561-573.

Veerappan AR. and Shanmugam S. 2008. Analysis for Flexibility in the ovality and thinning limits of pipe bends. ARPN Journal of Engineering Applications and Science, Vol.3, No. 1, pp. 31-41.

Veerappan AR., Shanmugam S. and Soundrapandian S. 2010. The accepting of pipe bends with ovality and thinning using finite element method. ASME Journal of Pressure Vessel Technology, Vol.132, No. 031204, pp. 1-9.

Yahiaoui K., Moffat D. G. and Moreton D. N. 2000. Piping elbows with cracks. Part II. Global finite element and experimental plastic loads under opening bending. Journal of Strain Analysis, Vol.35, pp. 47-57.

Yahiaoui K., Moreton D. N. and Moffat D. G. 2002. Evaluation of limit load data for cracked elbows under opening bending and comparison with existing solutions. International Journal of Pressure Vessels and Piping, Vol.79, pp. 27-36.

\section{Biographical notes}

T.Christo Michael received the ME in Computer Aided Design from B.S.A.R. Crescent Engineering College, Anna University in 2008, and pursuing PhD in the area of analysis in pipe bends at National Institute of Technology, Tiruchirappalli from July 2009 to till date. He has published 2 papers in international journals in area of analysis in pipe bends.

Dr.AR. Veerappan received the ME in Design and Production of Thermal Power Equipment from National Institute of Technology, Tiruchirappalli in 1994, and Ph.D in Stress analysis of pipe bends from National Institute of Technology, Tiruchirappalli in 2008 and was awarded gold medal for his research contribution. He is an Associate. Professor of Mechanical Engineering in National Institute of Technology, Tiruchirappalli. His research interests include simulation methods, stress analysis in pressure vessel and piping and solar energy. He has published over 10 papers in international journals.

S. Shanmugam received the ME in Production Engineering from PSG College of Technology in 1985, and Ph.D from Indian Institute of Technology Madras in 1991. He is a Professor of Mechanical Engineering in National Institute of Technology, Tiruchirappalli. His research interests include solar energy applications, simulation methods, design of pressure vessel and piping. He has published over 20 papers in international journals.

Received May 2011

Accepted December 2011

Final acceptance in revised form January 2011 